\title{
Subgingival Distribution of Microorganisms
}

\author{
Eija Könönen • Mervi Gürsoy
}

Published online: 20 September 2014

(C) Springer International Publishing AG 2014

\begin{abstract}
Composition of subgingival microbiotas has long been seen as being of primary importance in the etiology of periodontal diseases. Development of advanced molecular methods has improved our knowledge about the role of traditional periodontal pathogens as well as resulted in the recovery of novel pathogen candidates. Detection rates of these microorganisms vary considerably between geographical regions but also between ethnic groups within a country. We have gathered information of various types of microorganisms inhabiting subgingival sites of individuals living in different parts of the world for the present review, the purpose of which is to highlight the potential impact of geography and ethnicity on subgingival findings, especially in chronic periodontitis.
\end{abstract}

Keywords Bacteria $\cdot$ Biofilm $\cdot$ Dental plaque $\cdot$ Ethnicity Geographic locations · Gingiva $\cdot$ Microorganism · Molecular methods $\cdot$ Periodontal pathogen $\cdot$ Periodontitis $\cdot$ Population . Smoking $\cdot$ Viruses $\cdot$ Yeasts

\section{Introduction}

Each site in the human body harbors a typical microbiota of its own. A recent study looking for the bacterial

E. Könönen $(\bowtie) \cdot$ M. Gürsoy

Department of Periodontology, Institute of Dentistry, University of Turku, Lemminkäisenkatu 2, 20520 Turku, Finland

e-mail: eija.kononen@utu.fi

M. Gürsoy

e-mail: mervi.gursoy@utu.fi

E. Könönen

Oral Health Care, Welfare Division, City of Turku, Turku, Finland microbiome in ten selected sites of the digestive tract, including seven intraoral sites, of more than 200 healthy adults, revealed four clusters on the basis of a similar community composition $[1 \bullet]$. Tooth-associated bacterial communities, namely supra- and subgingival plaque, formed one cluster, being clearly distinct from those of other intraoral or extraoral sites. Furthermore, the major difference between these two types of dental biofilms was the lower redox potential subgingivally, leading to increased abundances of strictly anaerobic genera (e.g., Fusobacterium, Prevotella, and Treponema) in subgingival biofilms [1•]. Although Porphyromonas, Tannerella, and Treponema proved to be highly prevalent genera in the examined healthy adults, it is important to keep in mind that, at the species level, these genera include both periodontitis-associated and periodontal health-associated organisms.

Bacterial communities in subgingival sites are highly diverse [2], and this diversity increases in diseased conditions $[3 \cdot, 4,5]$ when the overall composition rather than a single pathogen determines the pathogenicity of these biofilm communities. Indeed, the microbial profiles of subgingival biofilms differ significantly with respect to periodontal health status; bacterial diversity is greatest in diseased sites of periodontitis patients, in comparison with shallow sites or with subgingival findings in subjects without periodontitis [3•].

Health behavior of an individual, such as smoking and oral hygiene, can considerably influence the composition and abundance of subgingival microbiotas. Smoking is known as an important risk factor for periodontitis, which could be, at least partly, explained by the microbial shift. It has been shown that, on one hand, smoking favors the rapid shift towards pathogen-enriched biofilms in periodontal pockets and, on the other hand, causes a decrease in the proportion of health-compatible species [6,7]. Oral hygiene has an 
impact on subgingival biofilms irrespective of the smoking status [8]. Gingival inflammation, however, did not lead to a distinct subgingival microbiome in periodontal pockets [9•].

The environment (geography) and genetic factors (ethnicity) may have a fundamental impact on microbial findings in the oral cavity $[10 \bullet \bullet, 11 \bullet \bullet$. In the present review, we give an overview of the distribution of subgingival microorganisms in subjects of different ethnic origin and/or living in different continents and countries.

\section{Dental Plaque Below the Gumline}

Four decades ago, it was demonstrated by electron microscopy techniques that the microbial composition of subgingival plaque differs from that of supragingival plaque and that the composition varies in relation to periodontal health status [4]. While both plaque types consisted mainly of coccoid cells with features of Gram-positive organisms in periodontal health, various types of bacterial populations with flagellated bacteria and spirochetes dominated in periodontal diseaseassociated subgingival plaques. Dental biofilm formation and maturation occur via intergeneric and bacteria-environment interactions [12]. The use of specific oligonucleotide probes and fluorescent in situ hybridization has confirmed the principal findings of the structure of dental plaque where specific bacterial taxa are localized in different layers of the tooth-attached biofilms [13]. In subgingival biofilms, the bottom layer is mainly composed of Actinomyces. The intermediate layer consists of Fusobacterium nucleatum, Tannerella forsythia, and possibly Tannerella-like organisms, while the Cytophaga-Flavobacterium-Bacteroides cluster and the Synergistes group A are located in the top layer. Known periodontal pathogens, Porphyromonas gingivalis, Porphyromonas endodontalis, Prevotella intermedia, and Parvimonas micra, form microcolonies, colonizing already formed biofilms, whereas spirochetes dominate outside the biofilm [13]. The gradual maturation and subsequentially changing microbial composition influence the pathogenicity of subgingival biofilms [5].

A wide variety of microorganisms colonizing dental plaque at the gingival margin and below the gumline have been suggested as potentially being harmful to periodontal tissues. These include several bacterial species but also not-yetcultivated phylotypes [2, 3•, 5, 9•, 14, 15], Archaea [16], some viruses as triggering organisms [17], and yeasts as opportunistic pathogens [18]. Among bacteria, Gramnegative species especially are considered major culprits of periodontal destruction due to their biologically active lipopolysaccharide-containing cell wall structure [19], although evidence on the involvement of various Grampositive species in periodontal pathogenesis is also considerable $[3 \bullet, 9 \bullet, 15,20-22]$.

\section{Role of Different Microorganisms as Periodontal Pathogens}

\section{Bacteria}

Etiologic agents of periodontal diseases include both known cultivable species and several not-yet-cultivable phylotypes. According to Socransky and Haffajee [5], the three redcomplex bacterial species, P. gingivalis, T. forsythia, and T. denticola, are the key pathogens, while Gram-negative P. intermedia, Prevotella nigrescens, F. nucleatum, Campylobacter rectus, and Campylobacter showae and Gram-positive P. micra, Eubacterium nodatum, and Streptococcus constellatus in the orange complex are putative pathogens. The use of open-ended molecular methods has further highlighted the composition of subgingival biofilms in disease. In the landmark study of Paster et al. [2], 347 species/ phylotypes were found in subgingival samples from 31 subjects (11 subjects with 'refractory periodontitis', nine with periodontitis, two with HIV-associated periodontitis, four with necrotizing ulcerative gingivitis, and five periodontally healthy subjects). The majority of the findings represented unknown bacterial taxa; for example, Synergistetes (formerly Deferribacteres) and TM7 organisms were common in subgingival plaque of patients with periodontal disease. $P$. endodontalis and two red-complex species, $P$. gingivalis and $T$. forsythia, were exclusively associated with the disease, whereas T. denticola was common both in health and disease. Gram-positive Atopobium parvulum, Atopobium rimae, Eubacterium saphenum, and Filifactor alocis were found as potential pathogens [2]. In fact, it has been suggested that Gram-positive bacteria, such as Filifactor and Peptostreptococcus, could be the major players in periodontal disease [22]. In a recent study, using 454 pyrosequencing of 16S rRNA genes, clear differences were observed between subgingival plaque samples collected from subjects with chronic periodontitis and periodontitis-free subjects, the major periodontitis-associated organisms being $F$. alocis, $P$. gingivalis, and T. denticola [3•]. Interestingly, in the latter study, most findings represented cultivable species.

Of the Gram-negative organisms, A. actinomycetemcomitans is considered a major periodontal pathogen in aggressive periodontitis, particularly in its localized form [10••], while $P$. gingivalis has been long known as a typical member of subgingival biofilms in patients with chronic periodontitis [5]. It is notable that, in some geographical areas, subjects with aggressive periodontitis are primarily infected by $P$. gingivalis [10••]. In young adults, $P$. gingivalis and $T$. forsythia have been connected with the progression of gingivitis to periodontitis $[23,24]$. Therefore, $T$. forsythia could be useful as an indicator bacterium of periodontal destruction in its early phase. In addition to $T$. denticola, other Treponema species, such as T. lecithinolyticum and T. socranskii, can also be harmful to 
periodontal tissues, and the presence of subgingival spirochetes has been linked to both chronic and aggressive forms of periodontitis [25, 26•]. Among Gram-positive organisms, F. alocis has the strongest evidence as a periodontal pathogen $[2,3 \cdot, 9 \bullet$, 15, 20, 22] but several Eubacterium species have also been strongly associated with chronic periodontitis $[9 \cdot, 21]$. Table 1 presents bacterial taxa found in chronic periodontitis, obtained in three recent studies using high-throughput $16 \mathrm{~S}$ rRNA pyrosequencing $[3 \cdot, 9 \cdot, 15]$.

There can be considerable differences in the pathogenicity between the clones and genotypes within a species. Of the A. actinomycetemcomitans serotypes, serotypes $\mathrm{b}$ and $\mathrm{c}$ seem to have an increased virulence, which may explain why they are commonly detected in subjects with aggressive

Table 1 Bacterial taxa considered as periodontal pathogens in chronic periodontitis. Data are adapted from three studies using 454pyrosequencing of the $16 \mathrm{~S}$ rRNA gene

\begin{tabular}{|c|c|c|}
\hline Phylum/Class & Bacterial species (phylotype) & Reference(s) \\
\hline \multirow[t]{7}{*}{ Bacteroidetes } & Capnocytophaga granulosa & {$[15]$} \\
\hline & Porphyromonas gingivalis & {$[3 \cdot, 9 \cdot, 15]$} \\
\hline & Porphyromonas endodontalis & {$[3 \cdot, 9 \bullet]$} \\
\hline & Prevotella denticola & {$[3 \bullet, 15]$} \\
\hline & Prevotella intermedia & {$[3 \bullet]$} \\
\hline & Prevotella tannerae & {$[3 \bullet]$} \\
\hline & Tannerella forsythia & {$[3 \cdot, 9 \cdot, 15]$} \\
\hline \multirow[t]{5}{*}{ Spirochaetes } & Treponema denticola & {$[3 \cdot, 9 \bullet]$} \\
\hline & Treponema lecithinolyticum & {$[3 \cdot, 9 \bullet]$} \\
\hline & Treponema maltophilum & {$[3 \cdot, 9 \bullet]$} \\
\hline & Treponema socranskii & {$[3 \cdot, 9 \bullet]$} \\
\hline & Treponema vincentii & {$[3 \bullet]$} \\
\hline Fusobacteria & Fusobacterium nucleatum & {$[15]$} \\
\hline \multirow[t]{3}{*}{ Proteobacteria } & Campylobacter gracilis & {$[15]$} \\
\hline & Campylobacter rectus & {$[3 \bullet]$} \\
\hline & Kingella oralis & {$[15]$} \\
\hline \multirow[t]{4}{*}{ Firmicutes/Negativicutes } & Anaeroglobus geminatus & {$[3 \bullet]$} \\
\hline & Dialister invisus & {$[15]$} \\
\hline & Dialister pneumosintes & {$[15]$} \\
\hline & Selenomonas sputigena & {$[3 \cdot, 9 \bullet, 15]$} \\
\hline Firmicutes/Bacilli & Streptococcus anginosus & {$[15]$} \\
\hline \multirow[t]{8}{*}{ Firmicutes/Clostridia } & Eubacterium brachy & {$[9 \bullet]$} \\
\hline & Eubacterium nodatum & {$[9 \bullet]$} \\
\hline & Eubacterium saburreum & {$[15]$} \\
\hline & Eubacterium saphenum & {$[3 \cdot, 9 \cdot, 15]$} \\
\hline & Filifactor alocis & {$[3 \cdot, 9 \bullet, 15]$} \\
\hline & Mogibacterium timidum & {$[9 \bullet, 15]$} \\
\hline & Parvimonas micra & {$[9 \bullet, 15]$} \\
\hline & Peptostreptococcus stomatis & {$[3 \bullet, 15]$} \\
\hline Synergistetes & & {$[3 \bullet, 9 \bullet, 15]$} \\
\hline TM7 & & {$[3 \bullet, 9 \bullet, 15]$} \\
\hline
\end{tabular}

periodontitis $[10 \bullet \bullet]$. Within serotype $b$, the JP2, a specific clone with highly enhanced leukotoxicity, exposes its carrier to high risk of aggressive periodontitis [27]. Variation in the virulence of $P$. gingivalis may depend on the type of its fimbriae. Most $P$. gingivalis-positive subjects carry a single genotype, and distinct fimbrial genotypes are found in periodontitis patients in comparison with periodontally healthy subjects; fimA type II, in particular, has been associated with periodontitis [28-32]. Overall, the distribution of different clonal types of periodontal pathogens may vary considerably, depending on the geographic location and/or ethnicity.

\section{Viruses}

To date, little is known about the oral and periodontal viromes. Most information on viruses in periodontal literature exists on two herpes viruses, Epstein-Barr virus (EBV) and cytomegalovirus (CMV) [17]. Significantly altered viral load found in deep periodontal pockets supports the role of viruses in the pathogenesis and progression of periodontal disease [33, 34]. On one hand, the predominance of bacteriophages, including bacteriolytic myoviruses, may have a role in shaping the bacterial microbiota and altering its diversity in subgingival biofilms; the proportions of myoviruses were highest in periodontitis, whereas siphoviruses were significantly more abundant in health [34]. On the other hand, herpes viruses, particularly CMV, possess several potential pathogenicity mechanisms that can lead to periodontal tissue destruction (see a comprehensive review by Contreras et al. [33]). Indeed, elevated genomic copies of EBV and CMV have been detected in subgingival plaque, especially in subjects with untreated or progressive periodontitis [17]. Moreover, higher detection rates of viral co-existence or virus-anaerobe synergy have been found in deep periodontitis lesions in comparison with healthy sites $[35,36]$. According to the herpes viral-bacterial interactive model [17], viruses are considered triggering organisms for periodontitis-associated bacteria; however, the role of subgingival virus load in the periodontal pathogenesis remains unsolved. In fact, the solidity of the theory is challenged by studies reporting high detection rates of herpes viruses in periodontally healthy subjects [35-37] or failing to detect any viral contribution to periodontitis lesions [38-40]. Conflicting results in the occurrence of periodontal herpes viruses may be explained, at least in part, by variations in the clinical and viral diagnostic methods used in different studies or by true population-, ethnicity-, or age-related differences.

\section{Yeasts}

Although yeasts are aerobic organisms, considerable detection rates (17-48 \%) have been reported from diseased periodontal pockets [41-45]. Candida albicans is clearly the most 
common Candida finding in subgingival samples, while other species, such as $C$. dubliniensis and $C$. parapsilosis, are much less common and often recovered together with $C$. albicans [42, 44-46]. Other yeast species are only occasionally isolated from immunocompetent subjects. In HIV-infected periodontitis patients, a high frequency of yeasts has been reported from subgingival samples [18]. In this study, including $54 \mathrm{HIV}$ patients, $55 \%$ had C. albicans, $48 \%$ C. dubliniensis, and $17 \%$ C. glabrata subgingivally, whereas only one healthy subject in the HIV-negative control group had a subgingival culture with light growth of $C$. albicans. The role of Candida in the periodontal pathogenesis, if any, has not been elucidated yet.

\section{Impact of Geography and Ethnicity}

Marked differences can be observed in the frequencies of periodontal pathogens among different populations, which may reflect the geography and ethnicity as well as the epidemiology of different forms of periodontal disease $[5,10 \bullet \bullet]$. Figure 1 presents polymerase chain reaction (PCR)-based detection rates of two known periodontal pathogens, $A$. actinomycetemcomitans and $P$. gingivalis, giving an overview at a glance on their presence in different regions of the world.

\section{Subgingival Microbial Findings in Different Countries}

Major bacterial findings reported in studies from different countries are summarized in Table 2 [31, 35, 47-66]. As can be seen, a variety of microbial identification methods, including culture, DNA-DNA checkerboard hybridization, and several types of PCR, was used in these studies. Besides different identification methods, inclusion criteria, disease definition, clinical status of selected subgingival sites, and subgingival sampling methods vary between studies. In addition, often a relatively small number of subjects, even divided in subgroups, have been examined, which brings about uncertainties when interpreting the data. Therefore, it is plausible that differences in prevalence rates are not caused by geography solely. Some of the studies included subject groups from several countries but otherwise used the same study design and methodology for investigating the collected samples, thus improving the reliability of the comparison. Two culturebased studies were conducted in the Netherlands and Spain [54] and in Spain, Chile, and Colombia [49], including around 40 chronic periodontitis patients in each study group. Despite the similarity of the two Spanish study groups, there were slight differences in detection rates of examined pathogens; for example, for $A$. actinomycetemcomitans $3 \%$ [54] versus $17 \%$ [49] and for T. forsythia $65 \%$ versus $36 \%$, respectively.
Except for the low rate of $3 \%$ for $A$. actinomycetemcomitans, the microorganism was found in a fifth of the subjects in Spain, Netherlands, Chile, and Colombia. In general, subgingival $P$. gingivalis was a prevalent finding (65-84\%) in chronic periodontitis patients; however, in the Netherlands the prevalence was only $37 \%$. Furthermore, $P$. intermedia/P. nigrescens was isolated from $19 \%$ of Chilean patients in contrast to high detection rates (73-97\%) in other populations examined. The most remarkable difference was observed for P. micra; it was detected in $97 \%$ of Dutch subjects but only in one patient in the Colombian study group. Another study [55], presenting data on subgingival samples from 259 periodontitis patients in the Netherlands and comparing culture and PCR for detecting periodontal target microorganisms confirmed this high detection rate of $P$. micra previously presented [54]. A PCR-based study compared the prevalence of periodontal pathogens between 88 German and 91 Korean subjects suffering from chronic periodontitis [56]. A. actinomycetemcomitans and $T$. denticola were more common in German than in Korean subjects (48\% vs $27 \%$ and $96 \%$ vs $81 \%$, respectively), whereas high rates of $T$. forsythia and $P$. gingivalis were found in both countries. In a study using checkerboard DNA-DNA hybridization, subgingival proportions of 40 microorganisms were compared between chronic periodontitis patients in the US, Brazil, Chile, and Sweden [67]. Marked differences were detected for 13 target microorganisms; for instance, the adjusted mean proportion of $P$. gingivalis in subgingival plaque was highest in Chile and that of T. forsythia in Brazil, whereas the lowest proportions of these species were found in Sweden [67].

The methodology utilized for the detection of herpes viruses is an important matter when comparing the prevalence rates between different studies. Nowadays, nested PCR is a popular technique for subgingival virus detection, and data are available from various study populations. For example, CMV in periodontitis patients versus periodontitis-free subjects has been reported as follows: $35 \%$ versus $12 \%$ in Canada [68], $50 \%$ versus $48 \%$ in Brazil [35], $50 \%$ versus $5 \%$ in Iran [59], and $79 \%$ versus $77 \%$ in China [36], respectively. In contrast, by real-time PCR, extremely low rates of CMV (0-2\%) both for periodontally healthy and diseased subjects have been obtained from studies conducted in the US, UK, and Germany [38-40]. In a demographically homogenous Chinese study population, including 143 patients with chronic periodontitis and 141 periodontitis-free subjects, genotype profiles of CMV differed in relation to the periodontal health status. While CMV gB-I predominated in healthy and gingivitis subjects, CMV gB-II alone or in combination with EBV-1 had a significant association with periodontitis [36]. According to nested PCR-based studies from Brazil, Iran, Japan, and China, EBV-1 (or EBV) is common in subgingival plaque collected from deepened pockets [35-37, 59]. Again, real-time PCR resulted in much lower detection rates of EBV, varying 

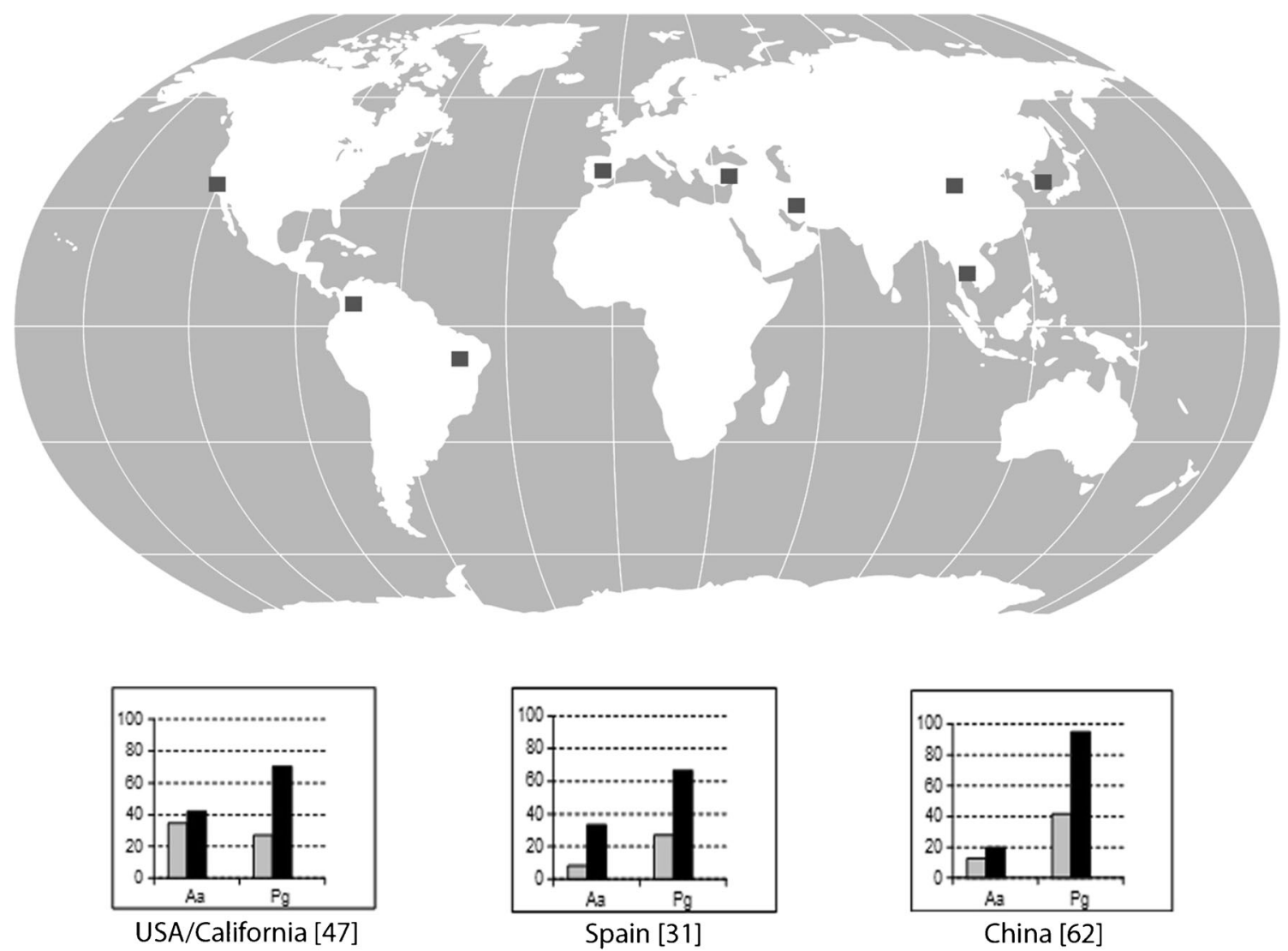
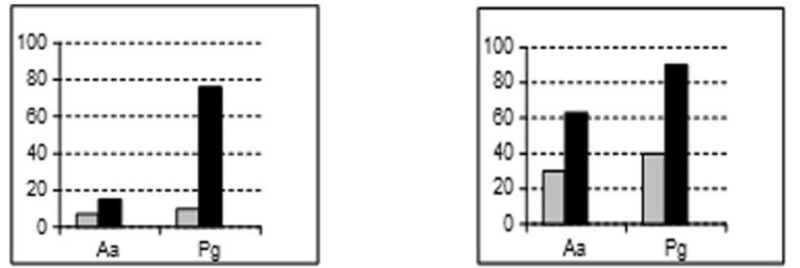

Turkey [43]

Colombia [50]

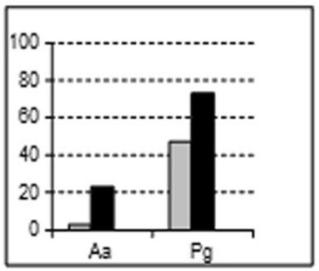

Brazil [35]

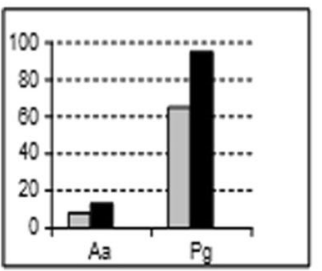

Iran [59]

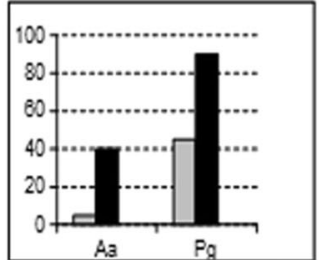

Thailand [66]

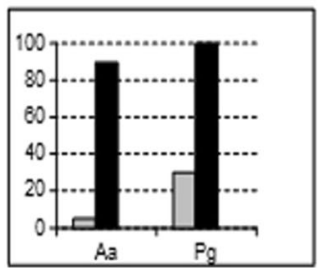

South Korea [64]
Fig. 1 Polymerase chain reaction (PCR)-based detection rates of A. actinomycetemcomitans and $P$. gingivalis in subjects with chronic periodontitis (black bars) and periodontitis-free controls (grey bars) in different regions of the world. The detailed information about the prevalence rates of the major periodontal pathogens is given in Table 2 between 6 and $28 \%$, in American, English, and German periodontitis patients [38-40]. Herpes simplex virus type 1 (HSV-1) was among the target microorganisms in the German study using real-time PCR [40] and in the Brazilian study using nested PCR [35], both studies including an aggressive periodontitis group. In the latter study, HSV-1 was found in $37 \%$ of the periodontally healthy subjects and in $87 \%$ of the patients with aggressive periodontitis, while the microorganism was found only in $2 \%$ of both healthy and diseased German subjects. It remains open whether this remarkable difference is explained by different methods or geography.

Subgingival yeasts in periodontitis patients have rather similar detection rates in different geographical locations. In two large-scale studies, $19.6 \%$ of the 535 samples collected in Sweden [41] and $16.8 \%$ of the 500 samples collected in the 
Table 2 Geographical distribution of major bacterial recoveries from subgingival plaque in chronic periodontitis subjects

\begin{tabular}{|c|c|c|c|c|c|c|c|c|c|c|c|c|c|c|}
\hline \multirow{2}{*}{$\begin{array}{l}\text { Country } \\
\text { [Reference] }\end{array}$} & \multicolumn{2}{|c|}{ Population } & \multirow[t]{2}{*}{ Method } & \multicolumn{11}{|c|}{ Prevalence $(\%)$} \\
\hline & $\mathrm{N}$ & $\begin{array}{l}\text { Age range } \\
(\text { mean } \pm \text { SD) }\end{array}$ & & $A a$ & $P g$ & $P i$ sensu lato & $P i$ & $P n$ & $T d$ & $T f$ & Syn & $\mathrm{Fa}$ & $P m$ & TM7 \\
\hline USA [47] & 101 & $35-83$ & PCR & 42 & 70 & & 57 & 85 & 76 & 83 & & & & \\
\hline Mexico [48] & 44 & $31-75$ & Checkerboard & 86 & 98 & & 95 & 93 & 95 & 96 & & & & \\
\hline Colombia [49] & 41 & $25-64$ & Culture & 17 & 66 & 73 & & & & 39 & & & 2 & \\
\hline Colombia [50] & 68 & $(42.3 \pm 11.3)$ & PCR & 15 & 77 & 75 & & & & 50 & & & & \\
\hline Colombia [51] & 325 & $(45.6 \pm 10.6)$ & PCR & 17 & 68 & & $\sim 27$ & $\sim 12$ & & 59 & & & & \\
\hline Brazil [35] & 30 & $(42.7 \pm 6.7)$ & PCR & 23 & 73 & & 87 & & & 33 & & & & \\
\hline Chile [49] & 37 & $31-60$ & Culture & 19 & 84 & 19 & & & & 16 & & & 30 & \\
\hline Cameroon [52] & 21 & $20-62$ & Checkerboard & 52 & 86 & & 86 & 91 & 67 & 82 & & & 91 & \\
\hline Sudan [53] & 25 & $22-70$ & $\begin{array}{l}\text { DNA probe/ } \\
\text { Culture }\end{array}$ & $16 / 28$ & $96 / 36$ & $\mathrm{NA} / 40$ & 76/NA & & & 96/NA & & & & \\
\hline Norway [53] & 18 & $30-61$ & Culture & 33 & 87 & 78 & & & & & & & & \\
\hline Netherlands [54] & 30 & $29-63$ & Culture & 23 & 37 & 90 & & & & 73 & & & 97 & \\
\hline Netherlands [55] & 259 & $>25$ & RT PCR/Culture & $27 / 22$ & $46 / 43$ & NA/64 & 83/NA & & & $89 / 83$ & & & & \\
\hline Germany [56] & 88 & $(43.3 \pm 8.6)$ & RNA probe & 48 & 82 & & & & 96 & 96 & & & & \\
\hline Switzerland [57] & 47 & $(50.5 \pm \mathrm{ND})$ & RT PCR & 19 & 81 & & 72 & & 89 & 96 & & & & \\
\hline Spain [49] & 36 & $26-67$ & Culture & 17 & 78 & 97 & & & & 36 & & & 61 & \\
\hline Spain [54] & 31 & $26-62$ & Culture & 3 & 65 & 74 & & & & 65 & & & 58 & \\
\hline Spain [31] & 33 & $(43.4 \pm \mathrm{ND})$ & PCR & 33 & 67 & & & & 49 & 70 & & & & \\
\hline Romania [58] & 36 & $30-68$ & Culture & 42 & 76 & 55 & & & & & & & & \\
\hline Turkey [43] & 14 & $37-59$ & PCR/Culture & $50 / \sim 43$ & $93 / \sim 71$ & $\mathrm{NA} / \sim 86$ & & & & $\mathrm{NA} / \sim 86$ & & & $\mathrm{NA} / \sim 29$ & \\
\hline Iran [59] & 40 & $(40.9 \pm 12.2)$ & Multiplex PCR & 13 & 95 & & & & & 75 & & & & \\
\hline Yemen [60] & 20 & $30-50$ & RT PCR & 68 & 98 & & & & 100 & 100 & & & 100 & \\
\hline Yemen [61] & 40 & $35-47$ & RT PCR & & 71 & & & & 91 & 100 & 100 & 100 & 100 & 95 \\
\hline China [62] & 60 & $(35.3 \pm 9.1)$ & RT PCR & 20 & 95 & & 98 & & & & & & & \\
\hline China [63] & 306 & $(52.2 \pm 9.6)$ & RT PCR & $\sim 11$ & $\sim 81$ & & $\sim 67$ & & $\sim 50$ & $\sim 47$ & & & & \\
\hline Korea [64] & 29 & $29-49$ & PCR & 90 & 100 & & 90 & & & 97 & & & 97 & \\
\hline Korea [56] & 90 & $(46.6 \pm 10.9)$ & RNA probe & 27 & 81 & & & & 81 & 89 & & & & \\
\hline Japan [65] & 20 & $(43.6 \pm 11.1)$ & RT PCR & 25 & 75 & & & & & 85 & & & & \\
\hline Thailand [66] & 20 & $(46.5 \pm 10.1)$ & PCR & 35 & 95 & & & & 80 & 95 & & & & \\
\hline
\end{tabular}

$A a=A$. actinomycetemcomitans $; F a=F$. alocis $; P g=P$. gingivalis $; P i=P$. intermedia $; P m=P$. micra $;$ Pn $=P$. nigrescens $;$ Syn $=$ Synergistetes $;$ Td $=$ T. denticola $; f=T$. forsythia $; \mathrm{NA}=$ no data available; $\mathrm{RT}$ PCR $=$ Real-time PCR

US [45] were reported to be positive for yeasts. In an Argentinian study population, C. albicans was found in $24 \%$, C. parapsilosis in $5.6 \%$, and C. dubliniensis in $4.4 \%$ of the 180 periodontitis patients examined [46]. Smaller studies conducted in Brazil [42], Turkey [43], and Ireland [44] have presented detection rates of $30 \%, 23 \%$, and $48 \%$, respectively, for yeasts in subgingival plaque from diseased periodontal pockets.

\section{Distribution of Some Virulent Clones/Types}

A comprehensive overview on the colonization of potential microorganisms related to aggressive periodontitis in geographically and ethnically diverse populations was recently provided by Könönen and Müller [10••]. Traditionally,
A. actinomycetemcomitans has been seen as the major pathogen and its leukotoxin production as the main virulence factor contributing to this form of periodontal disease. In general, of its seven serotypes, A. actinomycetemcomitans serotype $\mathrm{b}$ is common in periodontally diseased Caucasians in Europe, while in American and Asian subjects, serotype c dominates. However, serotype c and serotype a, in particular, are also common in A. actinomycetemcomitans-positive subjects without the disease (see Table 1 in the reference [10••]). In contrast, the presence of the specific JP2 clone results in a highly increased risk for aggressive periodontitis. This clone is nearly exclusively found in Moroccan adolescents and in some young populations of West African origin in Brazil and the US [10••]. Also, in chronic periodontitis patients colonized by A. actinomycetemcomitans, serotype distribution varies 
between countries. In Brazil, serotype c dominates and serotype a is relatively prevalent, contrasting with the findings in Finnish and Taiwanese patients where serotype $b$ dominates, while on the Eastern coast of the US, serotypes a, b, and c are distributed equally $[10 \bullet \bullet, 69]$.

Prevalence of fimbrial genotypes of $P$. gingivalis has been studied in various regions of the world. Although fimA type II seems to predominate in periodontitis patients irrespective of the geographical location, there are remarkable differences in the detection rates of other genotypes [28-32]. In Japan and China, the distribution of fimA genotypes proves to be similar; besides fimA type II, fimA type IV was common in subgingival plaque collected from subjects with periodontitis, whereas fimA type I was highly prevalent and also fimA type $\mathrm{V}$ was rather common in periodontally healthy subjects [28, 32]. In Brazil, the distribution differs as regards to fimA type IV, which was found in half of the periodontitis-free subjects but only occasionally in periodontitis patients [30]. In the latter study, including a multi-ethnic study population, the detection rates of P. gingivalis did not differ between Caucasians (88\%) and African-Brazilians (94\%) with periodontitis; however, no separate data on the prevalence of fimA genotypes in these ethnic groups were given.

\section{Ethnic Differences}

The influence of ethnicity is most reliably studied in countries with a multi-ethnic population. In the US, Craig et al. [70] examined a series of clinical, environmental, demographic, and microbiologic factors in an urban study population of 185 subjects, consisting of three minority groups living in the greater New York metropolitan area. Subgingival plaque samples were collected from 47 African-American, 40 AsianAmerican, and 27 Hispanic subjects and examined by the DNA-DNA checkerboard method. Although Actinomyces oris (formerly Actinomyces naeslundii genospecies 2) was the most common species in all groups, the mean proportions of some bacterial species differed significantly between the three ethnic groups; for example, P. micra (formerly Peptostreptococcus micros) was elevated in the AfricanAmerican group, whereas A. actinomycetemcomitans and Selenomonas noxia were elevated in the Asian-American group. However, elevated levels of periodontal pathogens were found especially in the unskilled group with worsened periodontal status, higher proportions of males and smokers, and being older than subjects in the skilled and professional groups [70]. In other words, the ethnicity itself was not the explanatory factor for differences seen in subgingival bacterial profiles.

In a study conducted in Los Angeles, California, oral samples (subgingival plaque, saliva) were collected from four ethnic groups, including 52 Caucasians, 50 Hispanics, 49 African-Americans, and 48 Asian-Americans, for PCR-based microbiologic analyses, including six periodontal bacteria [47]. The ethnicity, indeed, had an impact on the occurrence of target bacteria; AsianAmericans and Hispanics had a significantly increased risk for harboring A. actinomycetemcomitans and $P$. gingivalis subgingivally.

A recent US study was specifically targeted to examine the impact of ethnicity on the oral microbiome [11••, 71]. Altogether 192 periodontally and dentally healthy subjects, divided into Caucasian, African-American, Latino, and Chinese groups (48 subjects in each group), were carefully questioned for their demographics, oral hygiene (the frequency of brushing, flossing, smoking history, and visits to the dentist) and diet (standard American, Hispanic/Latino, Asian, and one not fitting to any of the three diets). When subgingival plaque samples from 25 subjects from each ethnic group were examined using an advanced sequencing method, discriminative microbial fingerprints with a $62 \%$ accuracy, $58 \%$ sensitivity, and $86 \%$ specificity were found. Although Caucasians and African-Americans shared a common food, nutritional and lifestyle heritage, a significant microbial divergence between these two groups was observed $[11 \bullet \bullet, 71]$, indicating that ethnicity itself is the determining factor for distinct bacterial profiles.

\section{Concluding Remarks}

To summarize the findings of the reviewed studies, it can be stated that subgingival detection rates of periodontal pathogens vary considerably in different regions of the word. The variation in methodologies leads in part to differences in microbiologic findings; however, geography and ethnicity have an impact on the composition of the human oral microbiota, including subgingival biofilms. Therefore, in studies with multi-ethnic study populations, it would be advisable to give the data separately for each ethnic group.

Acknowledgments We thank Klaus Könönen for generating the figure for this article.

\section{Compliance with Ethics Guidelines}

Conflict of Interest Eija Könönen and Mervi Gürsoy declare that they have no conflicts of interest.

Human and Animal Rights and Informed Consent This article does not contain any studies with human or animal subjects performed by any of the authors. 


\section{References}

Papers of particular interest, published recently, have been highlighted as:

- Of importance

.- Of major importance

1. Segata N, Haake SK, Mannon P, Lemon KP, Waldron L, Gevers D, et al. Composition of the adult digestive tract bacterial microbiome based on seven mouth surfaces, tonsils, throat and stool samples. Genome Biol. 2012;13:R42. As part of the Human Microbiome Project, this study demonstrates extensive niche specialization throughout the digestive tract of healthy adults.

2. Paster BJ, Boches SK, Galvin JL, Ericson RE, Lau CN, Levanos $\mathrm{VA}$, et al. Bacterial diversity in human subgingival plaque. $\mathrm{J}$ Bacteriol. 2001;183:3770-83.

3. Griffen AL, Beall CJ, Campbell JH, Firestone ND, Kumar PS, Yang ZK, et al. Distinct and complex bacterial profiles in human periodontitis and health revealed by $16 \mathrm{~S}$ pyrosequencing. ISME J. 2012;6:1176-85. The study presents comprehensive bacteriology of subgingival communities with fundamentally distinct profiles between deep and shallow sites of periodontitis subjects and between shallow sites of periodontally healthy and diseased individuals.

4. Listgarten MA. Structure of the microbial flora associated with periodontal health and disease in man. J Periodontol. 1976;47:1-18.

5. Socransky SS, Haffajee AD. Periodontal microbial ecology. Periodontol 2000. 2000;2005:38,135-87.

6. Kumar PS, Matthews CR, Joshi V, de Jager M, Aspiras M. Tobacco smoking affects bacterial acquisition and colonization in oral biofilms. Infect Immun. 2011;79:4730-8.

7. Mason MR, Preshaw PM, Nagaraja HN, Dabdoub SM, Rahman A, Kumar PS. The subgingival microbiome of clinically healthy current and never smokers. ISME J. 2014. doi:10.1038/ismej.2014. 114.

8. Gomes SC, Nonnenmacher C, Susin C, Oppermann RV, Mutters R, Marcantonio RA. The effect of a supragingival plaque-control regimen on the subgingival microbiota in smokers and neversmokers: evaluation by real-time polymerase chain reaction. J Periodontol. 2008;79:2297-304.

9. Abusleme L, Dupuy AK, Dutzan N, Silva N, Burleson JA, Strausbaugh LD, et al. The subgingival microbiome in health and periodontitis and its relationship with community biomass and inflammation. ISME J. 2013;7:1016-25. The study showed that increased inflammation was not associated with a distinct microbiome subgingivally. While total load of pathogens is increased in diseased pockets, this does not lead to loss of healthassociated bacteria, e.g., Actinomyces.

10.• Könönen E, Müller HP. Microbiology of aggressive periodontitis. Periodontol 2000. 2014;65:46-78. This article provides a comprehensive overview of the global carriage rates of potential pathogens associated with aggressive periodontitis.

11.• Mason MR, Nagaraja HN, Camerlengo T, Joshi V, Kumar PS. Deep sequencing identifies ethnicity-specific bacterial signatures in the oral microbiome. PLoS One. 2013;8:e77287. Discriminative microbial fingerprints in subgingival plaque were found between Caucasians and African-Americans who share a common food, nutritional and lifestyle heritage.

12. Kolenbrander PE, Palmer Jr RJ, Periasamy S, Jakubovics NS. Oral multispecies biofilm development and the key role of cell-cell distance. Nat Rev Microbiol. 2010;8:471-80.

13. Zijnge V, van Leeuwen MB, Degener JE, Abbas F, Thurnheer T, Gmür R, et al. Oral biofilm architecture on natural teeth. PLoS One. 2010;5:e9321.
14. Colombo AP, Boches SK, Cotton SL, Goodson JM, Kent R, Haffajee AD, et al. Comparisons of subgingival microbial profiles of refractory periodontitis, severe periodontitis, and periodontal health using the human oral microbe identification microarray. J Periodontol. 2009;80:1421-32.

15. Kistler JO, Booth V, Bradshaw DJ, Wade WG. Bacterial community development in experimental gingivitis. PLoS One. 2013;8: e71227.

16. Vianna ME, Holtgraewe S, Seyfarth I, Conrads G, Horz HP. Quantitative analysis of three hydrogenotrophic microbial groups, methanogenic archaea, sulfate-reducing bacteria, and acetogenic bacteria, within plaque biofilms associated with human periodontal disease. J Bacteriol. 2008;190:3779-85.

17. Slots J. Herpesviral-bacterial interactions in periodontal diseases. Periodontol 2000. 2010;52:117-40.

18. Jabra-Rizk MA, Ferreira SM, Sabet M, Falkler WA, Merz WG, Meiller TF. Recovery of Candida dubliniensis and other yeasts from human immunodeficiency virus-associated periodontal lesions. J Clin Microbiol. 2001;39:4520-2.

19. Darveau RP. The oral microbial consortium's interaction with the periodontal innate defense system. DNA Cell Biol. 2009;28:389-95.

20. Aruni W, Chioma O, Fletcher HM. Filifactor alocis: the newly discovered kid on the block with special talents. J Dent Res. 2014;93:725-32.

21. Haffajee AD, Teles RP, Socransky SS. Association of Eubacterium nodatum and Treponema denticola with human periodontitis lesions. Oral Microbiol Immunol. 2006;21:269-82.

22. Kumar PS, Griffen AL, Moeschberger ML, Leys EJ. Identification of candidate periodontal pathogens and beneficial species by quantitative 16S clonal analysis. J Clin Microbiol. 2005;43:3944-55.

23. Hamlet S, Ellwood R, Cullinan M, Worthington H, Palmer J, Bird P, et al. Persistent colonization with Tannerella forsythensis and loss of attachment in adolescents. J Dent Res. 2004;83:232-5.

24. Tanner AC, Kent Jr R, Kanasi E, Lu SC, Paster BJ, Sonis ST, et al. Clinical characteristics and microbiota of progressing slight chronic periodontitis in adults. J Clin Periodontol. 2007;34:917-30.

25. Moter A, Riep B, Haban V, Heuner K, Siebert G, Berning M, et al. Molecular epidemiology of oral treponemes in patients with periodontitis and in periodontitis-resistant subjects. J Clin Microbiol. 2006;44:3078-85.

26. You M, Mo S, Leung WK, Watt RM. Comparative analysis of oral treponemes associated with periodontal health and disease. BMC Infect Dis. 2013;13:174. In this study, significant differences were demonstrated in the composition of subgingival treponeme communities in periodontitis versus periodontitis-free individuals.

27. Haubek D, Ennibi OK, Poulsen K, Vaeth M, Poulsen S, Kilian M. Risk of aggressive periodontitis in adolescent carriers of the JP2 clone of Aggregatibacter (Actinobacillus) actinomycetemcomitans in Morocco: a prospective longitudinal cohort study. Lancet. 2008;371:237-42.

28. Amano A, Kuboniwa M, Nakagawa I, Akiyama S, Morisaki I, Hamada S. Prevalence of specific genotypes of Porphyromonas gingivalis fimA and periodontal health status. J Dent Res. 2000;79: 1664-8.

29. Beikler T, Peters U, Prajaneh S, Prior K, Ehmke B, Flemmig TF. Prevalence of Porphyromonas gingivalis fimA genotypes in Caucasians. Eur J Oral Sci. 2003;111:390-4.

30. Missailidis CG, Umeda JE, Ota-Tsuzuki C, Anzai D, Mayer MP. Distribution of fimA genotypes of Porphyromonas gingivalis in subjects with various periodontal conditions. Oral Microbiol Immunol. 2004;19:224-9.

31. Puig-Silla M, Dasí-Fernández F, Montiel-Company JM, AlmerichSilla JM. Prevalence of fimA genotypes of Porphyromonas gingivalis and other periodontal bacteria in a Spanish population with chronic periodontitis. Med Oral Patol Oral Cir Bucal. 2012;17: e1047-53. 
32. Zhao L, Wu YF, Meng S, Yang H, OuYang YL, Zhou XD. Prevalence of fimA genotypes of Porphyromonas gingivalis and periodontal health status in Chinese adults. J Periodontal Res. 2007;42:511-7.

33. Contreras A, Botero JE, Slots J. Biology and pathogenesis of cytomegalovirus in periodontal disease. Periodontol 2000. 2014;64:40-56.

34. Ly M, Abeles SR, Boehm TK, Robles-Sikisaka R, Naidu M, Santiago-Rodriguez T, et al. Altered oral viral ecology in association with periodontal disease. MBio. 2014;5:e01133-14.

35. Imbronito AV, Okuda OS, Maria de Freitas N, Moreira Lotufo RF, Nunes FD. Detection of herpesviruses and periodontal pathogens in subgingival plaque of patients with chronic periodontitis, generalized aggressive periodontitis, or gingivitis. J Periodontol. 2008;79: 2313-21.

36. Wu YM, Yan J, Ojcius DM, Chen LL, Gu ZY, Pan JP. Correlation between infections with different genotypes of human cytomegalovirus and Epstein-Barr virus in subgingival samples and periodontal status of patients. J Clin Microbiol. 2007;45:3665-70. Erratum in: J Clin Microbiol. 2008;46:836.

37. Kato A, Imai K, Ochiai K, Ogata Y. Higher prevalence of EpsteinBarr virus DNA in deeper periodontal pockets of chronic periodontitis in Japanese patients. PLoS One. 2013;8:e71990.

38. Dawson DR, Wang C, Danaher RJ, Lin Y, Kryscio RJ, Jacob RJ, et al. Real-time polymerase chain reaction to determine the prevalence and copy number of Epstein-Barr virus and cytomegalovirus DNA in subgingival plaque at individual healthy and periodontal disease sites. J Periodontol. 2009;80:1133-40.

39. Nibali L, Atkinson C, Griffiths P, Darbar U, Rakmanee T, Suvan J, et al. Low prevalence of subgingival viruses in periodontitis patients. J Clin Periodontol. 2009;36:928-32.

40. Stein JM, Said Yekta S, Kleines M, Ok D, Kasaj A, Reichert S, et al. Failure to detect an association between aggressive periodontitis and the prevalence of herpesviruses. J Clin Periodontol. 2013;40:1-7.

41. Dahlén G, Wikström M. Occurrence of enteric rods, staphylococci and Candida in subgingival samples. Oral Microbiol Immunol. 1995;10:42-6.

42. Canabaro A, Valle C, Farias MR, Santos FB, Lazera M, Wanke B. Association of subgingival colonization of Candida albicans and other yeasts with severity of chronic periodontitis. J Periodontal Res. 2013;48:428-32.

43. Doğan B, Antinheimo J, Cetiner D, Bodur A, Emingil G, Buduneli E, et al. Subgingival microflora in Turkish patients with periodontitis. J Periodontol. 2003;74:803-14.

44. McManus BA, Maguire R, Cashin PJ, Claffey N, Flint S, Abdulrahim MH, et al. Enrichment of multilocus sequence typing clade 1 with oral Candida albicans isolates in patients with untreated periodontitis. J Clin Microbiol. 2012;50:3335-44.

45. Slots J, Rams TE, Listgarten MA. Yeasts, enteric rods and pseudomonads in the subgingival flora of severe adult periodontitis. Oral Microbiol Immunol. 1988;3:47-52.

46. Jewtuchowicz VM, Mujica MT, Brusca MI, Sordelli N, Malzone $\mathrm{MC}$, Pola SJ, et al. Phenotypic and genotypic identification of Candida dubliniensis from subgingival sites in immunocompetent subjects in Argentina. Oral Microbiol Immunol. 2008;23:505-9.

47. Umeda M, Chen C, Bakker I, Contreras A, Morrison JL, Slots J. Risk indicators for harboring periodontal pathogens. J Periodontol. 1998;69:1111-8.

48. Ximenez-Fyvie LA, Almaguer-Flores A, Jacobo-Soto V, LaraCordoba M, Sanchez-Vargas LO, Alcantara-Maruri E. Description of the subgingival microbiota of periodontally untreated Mexican subjects: chronic periodontitis and periodontal health. J Periodontol. 2006;77:460-71.

49. Herrera D, Contreras A, Gamonal J, Oteo A, Jaramillo A, Silva N, et al. Subgingival microbial profiles in chronic periodontitis patients from Chile, Colombia and Spain. J Clin Periodontol. 2008;35:106-13.
50. Botero JE, Contreras A, Lafaurie G, Jaramillo A, Betancourt M, Arce RM. Occurrence of periodontopathic and superinfecting bacteria in chronic and aggressive periodontitis subjects in a Colombian population. J Periodontol. 2007;78:696-704.

51. Lafaurie GI, Contreras A, Barón A, Botero J, Mayorga-Fayad I, Jaramillo A, et al. Demographic, clinical, and microbial aspects of chronic and aggressive periodontitis in Colombia: a multicenter study. J Periodontol. 2007;78:629-39.

52. Ali RW, Johannessen AC, Dahlén G, Socransky SS, Skaug N. Comparison of the subgingival microbiota of periodontally healthy and diseased adults in northern Cameroon. J Clin Periodontol. 1997:24:830-5.

53. Ali RW, Bakken V, Nilsen R, Skaug N. Comparative detection frequency of 6 putative periodontal pathogens in Sudanese and Norwegian adult periodontitis patients. J Periodontol. 1994;65: 1046-52.

54. Sanz M, van Winkelhoff AJ, Herrera D, Dellemijn-Kippuw $\mathrm{N}$, Simón R, Winkel E. Differences in the composition of the subgingival microbiota of two periodontitis populations of different geographical origin. A comparison between Spain and The Netherlands. Eur J Oral Sci. 2000;108:38392.

55. Boutaga $\mathrm{K}$, van Winkelhoff AJ, Vandenbroucke-Grauls $\mathrm{CM}$, Savelkoul PH. The additional value of real-time PCR in the quantitative detection of periodontal pathogens. J Clin Periodontol. 2006;33:427-33.

56. Kim TS, Kang NW, Lee SB, Eickholz P, Pretzl B, Kim CK. Differences in subgingival microflora of Korean and German periodontal patients. Arch Oral Biol. 2009;54:223-9.

57. Cionca N, Giannopoulou C, Ugolotti G, Mombelli A. Microbiologic testing and outcomes of full-mouth scaling and root planing with or without amoxicillin/metronidazole in chronic periodontitis. J Periodontol. 2010;81:15-23.

58. Ali RW, Velcescu C, Jivanescu MC, Lofthus B, Skaug N. Prevalence of 6 putative periodontal pathogens in subgingival plaque samples from Romanian adult periodontitis patients. J Clin Periodontol. 1996;23:133-9.

59. Chalabi M, Rezaie F, Moghim S, Mogharehabed A, Rezaei M, Mehraban B. Periodontopathic bacteria and herpesviruses in chronic periodontitis. Mol Oral Microbiol. 2010;25:236-40.

60. Al-Hebshi NN, Shuga-Aldin HM, Al-Sharabi AK, Ghandour I. Subgingival periodontal pathogens associated with chronic periodontitis in Yemenis. BMC Oral Health. 2014;14:13.

61. Al-Hebshi NN, Al-Alimi A, Taiyeb-Ali T, Jaafar N. Quantitative analysis of classical and new putative periodontal pathogens in subgingival biofilm: a case-control study. J Periodontal Res. 2014.

62. He J, Huang W, Pan Z, Cui H, Qi G, Zhou X, et al. Quantitative analysis of microbiota in saliva, supragingival, and subgingival plaque of Chinese adults with chronic periodontitis. Clin Oral Investig. 2012;16:1579-88.

63. Li C, Liu J, Tan L, Yu N, Lin L, Geng F, et al. The sociodemographic characteristics, periodontal health status, and subgingival microbiota of patients with chronic periodontitis and type 2 diabetes mellitus: a case-control study in a Chinese population. J Periodontol. 2013;84:1058-66.

64. Choi BK, Park SH, Yoo YJ, Choi SH, Chai JK, Cho KS, et al. Detection of major putative periodontopathogens in Korean advanced adult periodontitis patients using a nucleic acid-based approach. J Periodontol. 2000;71:1387-94.

65. Tomita S, Komiya-Ito A, Imamura K, Kita D, Ota K, Takayama S, et al. Prevalence of Aggregatibacter actinomycetemcomitans, Porphyromonas gingivalis and Tannerella forsythia in Japanese patients with generalized chronic and aggressive periodontitis. Microb Pathog. 2013;61-62:11-5. 
66. Wara-aswapati N, Pitiphat W, Chanchaimongkon L, Taweechaisupapong S, Boch JA, Ishikawa I. Red bacterial complex is associated with the severity of chronic periodontitis in a Thai population. Oral Dis. 2009;15:354-9.

67. Haffajee AD, Bogren A, Hasturk H, Feres M, Lopez NJ, Socransky SS. Subgingival microbiota of chronic periodontitis subjects from different geographic locations. J Clin Periodontol. 2004;31:9961002.

68. Grenier G, Gagnon G, Grenier D. Detection of herpetic viruses in gingival crevicular fluid of patients suffering from periodontal diseases: prevalence and effect of treatment. Oral Microbiol Immunol. 2009;24:506-9.
69. Roman-Torres CV, Aquino DR, Cortelli SC, Franco GC, Dos Santos JG, Corraini P, et al. Prevalence and distribution of serotype-specific genotypes of Aggregatibacter actinomycetemcomitans in chronic periodontitis Brazilian subjects. Arch Oral Biol. 2010;55:242-8.

70. Craig RG, Boylan R, Yip J, Bamgboye P, Koutsoukos J, Mijares D, et al. Prevalence and risk indicators for destructive periodontal diseases in 3 urban American minority populations. J Clin Periodontol. 2001;28:524-35.

71. Mason MR, Nagaraja HN, Camerlengo T, Joshi V, Kumar PS Correction: deep sequencing identifies ethnicity-specific bacterial signatures in the oral microbiome. PLoS One. 2014;9:e99933. 